\title{
Bases del poder de los mercaderes de plata de la ciudad de México. Redes, control del Consulado y de la Casa de Moneda a fines del siglo XVII ${ }^{1 /}$
}

\author{
Bases of power of the silver merchants of Mexico City. \\ Networks, venality, Merchant guilds control \\ and the Mint at the end of the $17^{\text {th }}$ century
}

\author{
Guillermina del Valle Pavón \\ Instituto de Investigaciones \\ Dr. José María Luis Mora, México DF
}

En las últimas décadas del siglo XVII un pequeño grupo de mercaderes de la ciudad de México garantizaron la producción de la mayor parte de la plata que se producía en Nueva España. En el artículo se exponen las redes que articularon dichos mercaderes para adquirir la plata, el papel de los vínculos familiares y la importancia de las relaciones de confianza en el financiamiento de sus negocios. Se analiza la forma en que el crédito de los tratantes de plata garantizó el abasto de azogue, en particular cuando tomaron el control del Consulado de México y éste se hizo cargo de administrar la renta de alcabalas. Por último, se examina cómo la venalidad de los oficios reales permitió a dichos actores dominar la única Casa de Moneda de Nueva España, así como las prácticas ilícitas que llevaban a cabo en relación con la acuñación.

Palabras Clave: Mercaderes; Consulado; Redes; Venalidad; Mercurio; Ciudad de México; Plata;

Minería; Casa de Moneda; Acuñación; Crédito; Comercio.

In the last decades of the 17th century a small group of merchants from Mexico City guaranteed production of most silver produced in New Spain. This article presents the business networks established by these merchants to purchase silver, the role of family bonds and the importance of trust relationships to finance their ventures. It also analyzes how credit provided by silver merchants funded the mercury supply, specially after they took control of the Mexico City merchant guild which became responsible to collect alcabala taxes. Lastly, this study also examines how venality in royal positions allowed the same merchants to control the only mint in all of New Spain, as well as to illicitly adulterate coinage.

KEYwORDS: Merchants; Merchant Guilds; Networks; Venality; Mercury; Mexico city; Silver, Mining; Mint; Minting; Credit; Commerce.

1 Agradezco los valiosos comentarios de Arrigo Amadori, los cuales permitieron mejorar el presente trabajo. 
A lo largo del siglo XVII Nueva España adquirió una autonomía cada vez mayor con respecto a la metrópoli. Mientras que el poder de la corona decaía, las oligarquías del virreinato acrecentaban su control sobre la economía y la política. Los mercaderes de la ciudad de México constituyen el mejor ejemplo de este fenómeno, ya que fortalecieron su posición al ejercer un dominio creciente sobre la producción, circulación y amonedación de la plata. Siendo el metal blanco el principal medio de cambio de carácter internacional, los mercaderes en cuestión dominaban los circuitos comerciales legales e informales que articulaban Nueva España con la metrópoli, Filipinas, Perú y el Caribe, así como los intercambios al interior del virreinato. La posición de dichos actores sociales se veía favorecida por su pertenencia al Consulado de México, corporación que ejercía el monopolio de la justicia mercantil en Nueva España y representaba los intereses de sus miembros. ${ }^{2}$

El propósito del presente ensayo radica en analizar las bases del poder económico y político del puñado de mercaderes de plata que concentró el preciado metal, adquirió el control del Consulado y de la única Casa de Moneda de la Nueva España en las últimas décadas del siglo XVII. La historiografía ha planteado la importancia que tuvieron los vínculos interpersonales y las redes sociales en la configuración del sistema político de la monarquía hispánica. ${ }^{3}$ En el caso aquí estudiado, el análisis de las complejas redes de sociabilidad ${ }^{4}$ que configuraron los mercaderes de plata de la capital está estrechamente relacionado con las estructuras de poder de la Nueva España por los vínculos interpersonales que establecieron con los virreyes, las asociaciones que formaron con miembros del aparato judicial y administrativo, los lazos de confianza que tejieron con la jerarquía eclesiástica y los funcionarios reales, así como por el control que ejercieron sobre instituciones que desempeñaban un papel fundamental en la economía virreinal.

2 Acerca del Consulado de México véanse de Valle Pavón, 2002, 517-557 y 2007, 155-187.

3 Sobre el análisis de las redes y los actores sociales en la monarquía hispánica véanse Imizcoz, 1996, 13-50; y Ponce Leiva y Amadori, 2008, 15-42.

4 Michel Bertrand (1998, 103-133) proporciona una adecuada definición de las redes de sociabilidad: «el conjunto permanente o temporal de vínculos de naturaleza diversa que unen a los individuos entre sí [...] y los lleva a actuar de manera colectiva en una misma dirección para la obtención de resultados que interesan, si no directa y simultáneamente a la totalidad de sus miembros, por lo menos a una fracción importante de ellos.» Algunos historiadores han realizado estudios sobre redes valiéndose de la herramienta que permite graficar las redes sociales con el propósito de poder visualizar la forma en que se configuraban estas y las posiciones que ocupaban sus integrantes. Véanse como ejemplo los trabajos coordinados por Ibarra y Valle Pavón, Ponce Leiva y Amadori, 2008. 
Los mercaderes de plata de la capital mexicana han sido estudiados a fondo en las primeras décadas del siglo XVII, ${ }^{5}$ mientras que para fines de la centuria sólo se conoce su papel como habilitadores de la producción argentífera. ${ }^{6}$ A continuación veremos la forma en que los mercaderes de plata lograron dominar gran parte de la economía de Nueva España. En el primer apartado se examinan las complejas redes de negocios que articularon para asegurar la adquisición del metal blanco. A través del financiamiento de la minería establecieron relaciones de clientela con oficiales del erario, autoridades locales y magistrados que les proporcionaban beneficios privativos y ganancias extraordinarias. En la segunda sección se estudian los lazos familiares que les permitieron expandir sus casas mercantiles y asegurar el vínculo con la metrópoli. En la tercera parte se examinan las relaciones de confianza en que sustentaban el otorgamiento de crédito y la recepción de capitales. En el cuarto acápite se analiza la participación de los mercaderes en las compras de azogue, la importancia de su papel financiero cuando tomaron el control del Consulado y este se hizo cargo de administrar la renta de alcabalas que garantizó el reembolso de los capitales adelantados. Por último veremos cómo controlaron la Casa de Moneda mediante la adquisición de los principales oficios, así como las prácticas ilegales que realizaban en la acuñación de metales.

\section{Agentes y socios de los mercaderes de plata}

Los mercaderes de la ciudad de México desempeñaron un papel fundamental en el financiamiento de la producción minera y la acuñación de plata. La explotación argentífera demandaba inversiones cuantiosas en infraestructura, insumos y moneda para pagar los jornales, en tanto que era altamente arriesgada porque dependía de la riqueza de las vetas. Por otra parte, la amonedación se realizaba en la capital, en donde se ubica la única Casa de Moneda del virreinato, y era un proceso laborioso, dilatado y costoso debido a las técnicas empleadas para evitar la falsificación y el

5 Hoberman, 1991, realizó una investigación extraordinaria sobre dichos mercaderes en el periodo 1590-1660. García de León, 2003, 41-83, examinó los alcances de las redes establecidas en torno a los negociantes criptojudíos establecidos en Veracruz, cuyo punto nodal era un mercader de la ciudad de México.

6 En sus trabajos sobre el comercio en el norte de Nueva España, Huerta ha realizado importantes aportaciones sobre varios mercaderes de plata. Huerta, 2007, 71-85 y 85-116; de la misma autora, 2003, 17-40. 
cobro de derechos. Además, la administración de la Ceca carecía de un fondo en reales para intercambiarlo de inmediato por la plata en barras, por lo que quienes las presentaban tenían que esperar varios meses para que fueran acuñadas. Todas estas circunstancias transformaron a los mercaderes del Consulado de México en los principales aviadores de la producción argentífera, ${ }^{7}$ mientras que los más acaudalados controlaban el proceso de amonedación.

La redefinición de la política imperial sobre el aprovisionamiento de mercurio al Perú y la Nueva España a partir de la década de 1620 generó serios perjuicios a la explotación de los minerales de baja ley que abundaba en el virreinato del norte. Al tiempo que se padeció el desabasto del metal líquido, el erario novohispano suspendió las entregas de azogue a crédito a los mineros y exigió el pago de las deudas por dicho concepto. El Consulado de México protestó de manera enérgica contra tales disposiciones, desde 1622, y a mediados del decenio de 1630 los virreyes se quejaron acremente por el desabasto que se padecía. Los problemas relacionados con el suministro del mercurio condujeron a los mercaderes de México a fungir como fiadores de los mineros en las compras del metal y a involucrarse más profundamente en el financiamiento de la minería. ${ }^{8}$

Para asegurar la compra de grandes cantidades de plata los mercaderes en cuestión se valían de diversas estrategias. Establecían agentes en los reales de minas; otorgaban crédito a otros grandes mercaderes consulares y a tratantes de plata avecindados en los pueblos mineros; se valían de transportistas y viandantes que viajaban periódicamente a dichas poblaciones; y se asociaban con agentes del erario, justicias, autoridades locales y otros funcionarios emplazados en los centros de producción argentífera. ${ }^{9}$

En las últimas cuatro décadas del siglo XVII, los principales mercaderes de plata fueron José de Retes Largacha, su sobrino y socio, Dámaso de Zaldívar, Luis Sánchez de Tagle, Juan de Urrutia Retes, Diego del Castillo y su yerno, Domingo de Larrea. ${ }^{10}$ Aun cuando los primeros operaron princi-

7 Elhuyar, 1979, 8 y ss.; Fonseca y Urrutia, 1845, 230, 231.

8 Se hace referencia al informe del consulado del 30 de mayo de 1622, en la real cédula de 27 de julio de 1623 . Cuaderno $3^{\circ}$ que extracta varias cédulas y otros papeles cuyos asuntos son singulares. Archivo General de la Nación, México, Archivo Histórico de Hacienda (en adelante AGNM, AHH), 599-3, s/n. Bakewell, 1976, 209-249.

9 Bakewell, 1976, 290, 294, 295; Hoberman, 1998, 72-77; Huerta, 1997, 70-78; Huerta, 2003, 17-20.

10 El granadino Diego del Castillo, casó en 1673 a una de sus hijas adoptivas con Domingo Larrea, natural de Erive, en Alava, y cinco años después fundó con él una compañía para el tráfico de plata. Rubial García, 1992, 7, 14-16. 
palmente en Zacatecas y los dos últimos en San Luis Potosí, establecieron sociedades para habilitar a los mineros de ambas jurisdicciones, y de otras más, con el objeto de adquirir plata para amonedarla. José de Retes Largacha compró el oficio de apartador general de metales en $1655,{ }^{11}$ y se asoció con José de Quesada Cabreros, quien había sido teniente del tesorero de la Casa de Moneda durante muchos años. ${ }^{12}$ Esta compañía reemplazó la ausencia del mercader Simón de Haro, que fue el mayor acuñador de Nueva España hasta 1655, año en el que falleció. ${ }^{13}$ Juan de Urrutia Retes y Luis Sánchez de Tagle también se dedicaban a la acuñación. En 1700 el sobrino del segundo compró el oficio de tallador mayor de la Ceca. ${ }^{14}$ De 1690 a 1710 don Luis remitió entre 30,000 y 130,000 pesos anuales a sus agentes en la ciudad de Zacatecas, principal centro de redistribución del norte de Nueva España. ${ }^{15}$ Dichas cifras proporcionan una idea del monto de las operaciones que realizaba Sánchez de Tagle en la cúspide de su carrera.

Los mercaderes de plata otorgaban crédito a otros miembros del Consulado de México para que compraran el metal en los reales mineros, a través de sus agentes y factores. A petición del mercader Juan de Bassoco, Sánchez de Tagle prestó dinero a tres comerciantes avecindados en Parral, a través del agente que el primero tenía en dicha población. ${ }^{16}$ En 1674, año en que José de Retes Largacha fue prior del cuerpo mercantil de México, suministró grandes sumas a Diego García Cano para habilitar a otro comerciante de Parral, que entonces era uno de los reales más productivos del virreinato. ${ }^{17}$ La complejidad de las redes de negocios establecidas por los mercaderes de plata, se ilustra a través de la siguiente operación. En 1692 el conde de Santa Rosa, minero de Zacatecas, pagó a la Real

11 Retes pagó 60,000 pesos por dicho oficio, cuya función consistía en separar de la plata pequeñas cantidades de oro, cobrando 6 reales por cada marco de plata. Elhuyar, 1979, 48, 49.

12 Huerta, 2007, 85-116. De 1629 a 1659 o 1660, el propietario de dicho oficio fue el mercader Juan Lorenzo de Vera, cuyo padre Diego Matías de Vera, lo había comprado en 1607 para su hijo Melchor, quien había muerto sin sucesión en 1629. Hoberman, 1991, 67, 87; Pazos y Pazos, 1999, 299.

13 Al igual que Simón de Haro, Retes Largacha y Quesada Cabreros fueron banqueros de los virreyes en las décadas de 1640 y 1650. Hoberman, 1991, 177. Haro había estado implicado en el contrabando de grandes cantidades de plata. Cuando fue prior del consulado se acumularon grandes adeudos con la real Hacienda, por lo que a su muerte el virrey mandó confiscar sus bienes. Valle Pavón, 2003, 54-56.

14 Testamento de Luis Sánchez de Tagle, México, 28 de abril de 1714. AGNM, Notario 692, Francisco de Valdés, v. 4705.

15 Huerta, 2003, 24.

16 Dichos comerciantes eran Cristóbal de Orrantia, Pedro de Bassoco y Manuel Iriarte. Huerta, 2003, 24, 30, 31.

17 Por tal motivo se estableció en Parral la capital de Nueva Vizcaya, en 1667. Huerta, 1997, 70-78. 
Hacienda 6,000 pesos, probablemente por la compra de azogue, con un pagaré firmado por un comerciante de Zacatecas, el cual sería cubierto por Luis Sánchez de Tagle y otro importante aviador de la ciudad de México. ${ }^{18}$

Los tratantes de plata también integraron en sus redes a los dueños de carretas y arrieros que acarreaban moneda y mercancías a los pueblos mineros, de donde regresaban a México cargados de plata en pasta. Los transportistas operaban como fiadores de los comerciantes residentes en los reales de minas que pedían crédito a los mercaderes de México. Sánchez de Tagle habilitó la cuadrilla de carros del general Juan Fernández de Retana, quien se valió de su sobrino, el capitán Juan González de Retana, para obtener crédito del mercader. Algunos forjaron grandes empresas, y así, un carretero que trabajaba la ruta México-Parral, entre otros destinos llegó a poseer treinta carros, mil mulas, cuarenta caballos y diez esclavos. ${ }^{19}$

Los principales agentes y socios de los mercaderes de plata fueron los oficiales del real erario, las justicias locales y las autoridades municipales. Esto se explica por las mínimas remuneraciones que percibían, porque otorgaban fianzas elevadas para ser nombrados, así como por el aumento en la cantidad y calidad de los cargos vendibles. La venta de oficios, regidurías y magistraturas inició a fines del siglo XVI y se incrementó de manera creciente a partir de la década de $1640 .{ }^{20}$ Gobernaciones provinciales, como el corregimiento de Zacatecas, empezaron a otorgarse por dinero en la década de $1670 .{ }^{21}$ Los alcaldes mayores y los corregidores recaudaban los derechos sobre la producción de metales y vendían el mercurio en los pueblos mineros de los distritos de la Audiencia de México, como Taxco y Pachuca, así como en los reales de Nueva Galicia y Nueva Vizcaya en donde no había cajas reales.22

Los mercaderes de plata financiaban a los funcionarios del erario, los jueces y las autoridades locales para que pagaran sus nombramientos y las garantías exigidas por la Hacienda. ${ }^{23}$ En algunos casos los resguar-

18 Langue, 1999, 88.

19 Huerta, 1997, 73, 74, 76 y Huerta, 2003, 26, 27.

20 Muro, 1982, 52, 53, 58.

21 En 1675 se concedió el corregimiento de Zacatecas a Bernardo Zumbil y Echarri a cambio de un donativo de 10.000 pesos. Bakewell, 1976, 132, 133.

22 Bakewell, 1976; Lang, 1977, 211-213, 233-239; Hoberman, 1998, 73.

23 El monto de las fianzas se determinaba de acuerdo con los derechos reales que los agentes del erario tenían que cobrar y el valor del mercurio asignado anualmente, en algunos casos esas garantías llegaron a ascender a 40,000 pesos. Muro, 1982, 52, 53, 58; Hoberman, 1991, 174; Bertrand, 1999, 244. Véase la tabla sobre las fianzas exigidas a los alcaldes de varios distritos mineros de 1600 a 1630 , en Lang, 1977, 231-232. 
dos eran tan elevados que se reunían entre varios sujetos que formaban asociaciones de fiadores. ${ }^{24} \mathrm{~A}$ cambio del riesgo que corrían los mercaderes al otorgar dicho crédito obtenían a los mejores agentes en los reales mineros, ${ }^{25}$ a pesar de que los oficiales reales tenían prohibido realizar contrataciones. ${ }^{26}$ Entre los favores ilícitos que los oficiales y justicias reales otorgaban a sus benefactores se destaca la evasión de derechos sobre la producción de plata y el cobro del derecho de diezmo que se imponía a los mineros, en lugar del quinto que pagaban a los rescatadores. ${ }^{27}$ Asimismo les garantizaban el abasto privilegiado de mercurio. ${ }^{28}$ Las justicias locales brindaban además apoyo a los mercaderes en los pleitos contra sus acreedores. ${ }^{29}$ Mientras que los regidores y alguaciles de los Cabildos mineros les proporcionaban información privilegiada sobre la situación de las minas y haciendas de beneficio, circunstancia que disminuía los riesgos del avío. ${ }^{30}$

Los tratantes de plata también establecieron compañías con los gobernadores de las provincias mineras que tenían bajo su control a los jueces de provincia. José Sáenz de Retes y Dámaso de Zaldívar y Retes, en la década de 1670, formaron sociedad con el gobernador de Nueva Vizcaya, que dominaba el comercio interregional a través de los alcaldes mayores. ${ }^{31}$

La defraudación del patrimonio regio se facilitaba cuando los oficiales del erario se aliaban con sus colegas, con los alcaldes mayores y los miembros del Cabildo. Hubo casos en que los últimos colaboraron para que sus allegados compraran los oficios de la Real Hacienda o pagaran la fianza requerida. Mercaderes como José de Retes Largacha adquirieron gran-

24 Hoberman, 1991, 173-176. Puede verse parte de un documento de garantía otorgado por un fiador del alcalde mayor de Taxco en 1769, en Lang, 1977, 232.

25 Sobre las complejas redes de interdependencia que los funcionarios reales establecieron con los mercaderes que los financiaban y los peligros que éstos corrían, véanse Hoberman, 1991, 166; y Bertrand, 1999, 236-254.

26 Acerca de la habilitación de la minería por parte de los corregidores de Zacatecas véase Bakewell, 1976, 126, 132-136. Y sobre el comercio que realizaban los alcaldes mayores de San Luis: Lang, 1977, 233, 234.

27 Bakewell, 1976, 290; Hoberman, 1998, 72-77.

28 Es probable que los apoderados de los alcaldes mayores y los oficiales del erario a nivel local, que les despachaban el azogue desde México, fueran los mismos mercaderes que los habilitaban. Lang, 1977, 207, 208, 210.

29 Hoberman, 1998, 73.

30 Algunos munícipes llegaban a distribuir la mano de obra en función de sus intereses y los de sus allegados. Langue, 1999, 48-49.

31 Huerta, 1997, 76 y Huerta, 2007, 105, 106. 
des cantidades de plata de rescate a través de José de Villareal, alguacil mayor del Cabildo de Zacatecas entre 1654 y 1680. Retes también compró plata de rescate al corregidor de Zacatecas que estuvo en funciones de 1662 a 1667, quien operaba a través del alguacil mayor, el alférez y un regidor del Cabildo, así como del oficial de la real caja. Igualmente se asoció con los corregidores que estuvieron en funciones hasta 1684,,$^{32}$ Algunos agentes del erario contaron con el apoyo de los oficiales del tesoro de la ciudad de México para realizar prácticas ilegales, circunstancia que fue propiciada por la venta de dichos oficios. ${ }^{33}$

Cuando llegaban a comprobarse los manejos ilícitos de los oficiales reales y las justicias locales, no necesariamente se aplicaban castigos severos. Las autoridades imponían a los transgresores multas, u otras formas de restitución. Los visitadores y quienes realizaban los juicios de residencia veían limitadas sus actuaciones, entre otras razones, por los vínculos profundos que las oligarquías locales tenían con los magistrados. ${ }^{34}$ Francisco Gómez Rendón, que fue tesorero de la real caja de Zacatecas durante más de cincuenta años, realizó un intenso tráfico de metales en colaboración con el factor de la misma tesorería y los miembros del Cabildo. Entre estos se distinguió el alguacil mayor José de Villareal, quien, como vimos, era habilitado por los principales mercaderes de México. Los vínculos establecidos por Gómez Rendón, que incluían a dos oidores de la Audiencia de Guadalajara, le permitieron librar con éxito la visita de que fue objeto a fines de la década de 1660, de la cual, incluso, salió fortalecido. ${ }^{35}$ Uno de los pocos corregidores de Zacatecas a quienes se realizó juicio de residencia en 1683, se defendió de la acusación de haber habilitado a los mineros de manera ilegal, argumentando que había recibido el crédito de los mercaderes de la capital en beneficio de la minería de la región. ${ }^{36}$

Las ganancias extraordinarias que se obtenían en el desempeño de las magistraturas y oficios locales, condujeron a los mercaderes de pla-

32 Entre 1659 y 1669, Retes entregó a Villarreal 609, 800 pesos en moneda y recibió a cambio 601,750 pesos del metal en pasta. Bakewell, 1976, 294, 295; Huerta, 2007, 73-75 y Huerta, 2003, $17-20$.

33 Muro, 1982, 57, 58; Bertrand, 1999, 247-262, 265, 266.

34 Muro, 1982, 52, 53, 55, 56; Hoberman, 1991,148.

35 Bertrand, 1999, 262-264. En cambio, Huerta sostiene que los fraudes que realizaban Gómez Rendón y Villarreal concluyeron a fines de la década de 1670, cuando fueron encarcelados. Huerta, 1997, 74 y 2007, 104, 105.

36 Bakewell, 1976, 132. 
ta a adquirir dichos cargos para sus parientes cercanos, ${ }^{37} \mathrm{y}$ a incorporar a quienes los desempeñaban a sus familias a través del matrimonio. ${ }^{38} \mathrm{El}$ cuñado de Dámaso de Zaldívar y Retes, Buenaventura de la Paz, era contador de la caja de San Luis Potosí, en donde se encontraba la agencia del apartador de plata y oro que pertenecía a la familia Retes-Zaldívar. ${ }^{39}$ Domingo Larrea, quien en 1678 formó compañía para el trato de plata con su suegro Diego del Castillo, poco después apoyó a su hermano Juan de Larrea para que obtuviera la tesorería de la caja de Pachuca. ${ }^{40}$ Más adelante veremos cómo Pedro Sánchez de Tagle, sobrino del mercader de plata Luis Sánchez de Tagle, casó a una de sus hijas con el tesorero del real erario de Pachuca, así como los beneficios que obtuvo de esta unión.

En los cuadros números 1 y 2 sobre los agentes de José de Retes Largacha y Luis Sánchez de Tagle en las principales poblaciones mineras, se aprecia la relevancia que tuvieron los oficiales del erario, las justicias y autoridades locales en las redes que vertebraron dichos mercaderes. Este fenómeno también puede verse en los grafos que se presentan. Como puede verse en dichos cuadros y grafos, las tramas tejidas por los mercaderes de plata se concentraban en los centros mineros más importantes, como Zacatecas, Sombrerete y San Luis Potosí. No obstante, también articulaban otros reales, algunos de los cuales se ubicaban en lugares remotos, como Santa Rosa Cusihuiriachic, población de la Sierra Tarahumara que estuvo en bonanza entre 1690 y $1702 .{ }^{41}$

37 En 1660 el Consejo de Indias planteó a la corona, «aquellos que compran puestos que se venden por 8,000 pesos son, en su mayor parte, ricos mercaderes que lo hacen para beneficiar sus negocios y defraudar las rentas recales» porque en las Indias «sólo es necesaria la apariencia de oficial real para que el poseedor goce de inmunidad ante una persecución». Hoberman, 1991, 155. Sobre los mercaderes que compraron oficios del Tesoro real y Alcaldías Mayores a partir de las décadas de 1620 y 1630, véase Ibidem, 154-157, 174-176.

38 El vizcaíno Juan García Ramón se asoció en 1664 con su paisano Felipe Vélez Escalante, alcalde mayor de Sombrerete, a quien dio en matrimonio su hija Francisca. Huerta, 2003, 25.

39 José Retes Largacha se había casado, al inicio de la década de 1670, con María de Paz y Vera, hija del comerciante gallego Pedro de Paz, primo de su ex socio Quesada Cabreros. En 1677, cuando Retes Largacha se asoció con sus sobrinos José Sáenz de Retes y Dámaso Zaldívar y Retes, arregló el matrimonio de este último con la hermana menor de su esposa, Beatriz de Paz y Vera, la cual no llevó dote al matrimonio. Huerta, 1997, 78, 80.

40 Diego del Castillo murió en 1683 y unos meses después Domingo de Larrea fue nombrado caballero de Santiago. Larrea logró que se otorgaran a sus hijos los hábitos de Alcántara y Santiago, en 1692, sin embargo, ninguno se hizo cargo del negocio del tráfico de plata. Domingo Larrea murió en 1697. Rubial García, 1992, 7, 14-16.

41 Huerta, 2003, 24, 29-31. 
GUILLERMINA DEL VALLE PAVÓN

\begin{tabular}{|c|c|c|c|}
\hline \multicolumn{4}{|c|}{$\begin{array}{l}\text { CUADRO NÚMERO 1. AGENTES DE LUIS SÁNCHEZ DE TAGLE } \\
\text { EN LOS CENTROS MINEROS DE NUEVA ESPAÑA }\end{array}$} \\
\hline Fernández de la Reguera, Juan & Cusihuiriachic & agente & \\
\hline Minaur y Murga, Francisco & Cusihuiriachic & agente & \\
\hline Fernández de Retana, Juan & Parral & dueño cuadrilla de carros & \\
\hline González de Retana, Juan & Parral & recibió crédito para tío Fdez Retana & \\
\hline Pérez Machargo, Antonio & Parral & agente & \\
\hline Vélez de la Torre, Juan & S L Potosí-Charcas & rescatador de plata & \\
\hline Campa Cos, Juan de la & San Luis Potosí & rescatador de plata & \\
\hline Espineda Millán, José Fco. & San Luis Potosí & rescatador, aviador indep, minero & \\
\hline Vargas Machuca, Juan & San Luis Potosí & rescatador de plata & \\
\hline Vélez de la Torre, Antonio & San Luis Potosí & tesorero de rl caja, rescatador & montañés \\
\hline Bustamante, Domingo Alonso de & Sombrerete & & \\
\hline Cosío Guerra, Antonio de & Sombrerete & & \\
\hline Díaz de Tagle, Francisco & Sombrerete & & \\
\hline Escandón, Tomás & Sombrerete & & \\
\hline Escorza, Juan Bautista & Sombrerete & hacendado y comandante Presidio & \\
\hline González de Quintana, Domingo & Sombrerete & & \\
\hline Menéndez, Toribio & Sombrerete & & \\
\hline Polanco, Francisco de & Sombrerete & & \\
\hline Velarde Cosío, Pedro & Sombrerete & & \\
\hline Vélez Escalante, Felipe & Sombrerete & alcalde mayor & Vizcaíno \\
\hline Cos, Antonio de & Sombrerete, Llerena & oficial de la real caja & Montañés \\
\hline González Calderón, Domingo & Sombrerete, Llerena & oficial de la real caja & Montañés \\
\hline Argüelles Valdés, Juan de & Zacatecas & & \\
\hline Corona, Andrés Tenorio & Zacatecas & & \\
\hline Larrañaga, Gaspar de & Zacatecas & ensayador y balanzario caja real & \\
\hline Roldán, Andrés & Zacatecas & 1679 enviado por Sánchez de Tagle & \\
\hline Sánchez de Tagle, Pedro & Zacatecas & & \\
\hline Valdés, Andrés Tenorio & Zacatecas & & \\
\hline Villaurrutia, José de & Zacatecas & rescatador de plata desde 1684 & \\
\hline Villareal, José de* & Zacatecas & alguacil mayor cabildo $1654-1680$ & \\
\hline
\end{tabular}

Fuentes: Huerta, Comerciantes, 2003; *Bakewell, 1976 p. 294. 
BASES DEL PODER DE LOS MERCADERES DE PLATA DE LA CIUDAD DE MÉXICO

\begin{tabular}{|c|c|c|c|}
\hline \multicolumn{4}{|c|}{$\begin{array}{l}\text { CUADRO 2. AGENTES DE JOSÉ DE RETES LARGACHA } \\
\text { EN LOS CENTROS MINEROS DE NUEVA ESPAÑA }\end{array}$} \\
\hline Fernández Pacheco, Andrés & Guadalajara & comerciante & \\
\hline Aguilar, Francisco de & Guadiana & alguacil mayor & \\
\hline López, Martín & México & $\begin{array}{l}\text { ensayador y balanzario real } \\
\text { caja }\end{array}$ & \\
\hline $\begin{array}{l}\text { García Salcedo, José, mariscal de } \\
\text { campo }\end{array}$ & Nueva Vizcaya & gobernador & Vizcaíno \\
\hline Villanueva Zapata, Gaspar de & Pachuca & alcalde mayor & \\
\hline Correa de Aguilar, Francisco & Parral & $\begin{array}{l}\text { comerciante, tesorero Sta. } \\
\text { Cruzada }\end{array}$ & \\
\hline Vega y Salazar, Jerónimo & Parral & apoderado & \\
\hline Álvarez, Juan & San Luis Potosí & oficial mayor real caja & \\
\hline Estrada, Bartolomé de & San Luis Potosí & alcalde mayor & \\
\hline Paz, Buenaventura de & San Luis Potosí & $\begin{array}{l}\text { Contador caja, cuñado } \\
\text { Dámaso Zaldívar }\end{array}$ & \\
\hline Zaldívar y Retes, Damián de & San Luis Potosí & sobrino y apoderado & Vizcaíno \\
\hline Sáez de Retes, Gabriel de & San Luis Potosí & sobrino y apoderado & Vizcaíno \\
\hline Orihuela, Domingo de & San Luis Potosí & apoderado & \\
\hline Zaldívar y Retes, Diego de & San Luis Potosí & sobrino y apoderado & Vizcaíno \\
\hline $\begin{array}{l}\text { Terán de los Ríos, Domingo, } \\
\text { general }\end{array}$ & San Luis Potosí & $\begin{array}{l}\text { alcalde mayor S Luis Potosí, } \\
\text { crédito }\end{array}$ & \\
\hline Artaza, Pedro de & San Luis Potosí & comerciante, pide crédito & $\begin{array}{l}\text { agente Saldivar-Retes } \\
1690 \mathrm{~s}\end{array}$ \\
\hline Jara, Jerónimo de & San Luis Potosí & comerciante, pide crédito & $\begin{array}{l}\text { agente Saldivar-Retes } \\
1690 \mathrm{~s}\end{array}$ \\
\hline Vega, Juan de & San Luis Potosí & alcalde mayor & $\begin{array}{l}\text { agente Saldivar-Retes } \\
1690 \mathrm{~s}\end{array}$ \\
\hline Cerezo Caballero, Juan de & Tlalpujahua & alcalde mayor & \\
\hline Estrada, Andrés de, general & Zacatecas & corregidor 1679-1684 & \\
\hline Manrique de Vargas, García & Zacatecas & corregidor 1662-1667 & \\
\hline Miño de Taboada Saldivar, Juan & Zacatecas & corregidor 1667- & \\
\hline Villareal, José de & Zacatecas & alguacil mayor 1659-1669 & \\
\hline Rada, Martín de & Zacatecas & contador caja & \\
\hline Arroyo Santerváez, José de & Zacatecas & regidor de Zacatecas & \\
\hline Castorena, Juan & Zacatecas & $\begin{array}{l}\text { alguacil yerno de José de } \\
\text { Villareal }\end{array}$ & $\begin{array}{l}\text { embargo bienes de } \\
\text { Villareal }\end{array}$ \\
\hline Freire Somorostro, Tomás & Zacatecas & corregidor & $\begin{array}{l}\text { embargo bienes por } \\
\text { deudas }\end{array}$ \\
\hline Mejía de Aguilar, José & & carretero & \\
\hline
\end{tabular}

Fuente: Huerta, "Retes", 1997; Lange, Señores, 


\section{Importancia de las redes familiares}

En las sociedades de Antiguo Régimen tenían gran importancia las relaciones de parentesco que se fundaban en el dominio jerárquico y las solidaridades tradicionales. Los mercaderes de plata consolidaron sus empresas con el apoyo de la familia extensa. Procedentes de las montañas de Santander y las Provincias Vascongadas, dichos negociantes llamaron a sus sobrinos, con quienes compartían valores comunes como la lealtad y el empeño en el trabajo, para integrarlos a sus casas. Esta práctica propiciaba la formación de cadenas migratorias que se reproducían a través de varias generaciones. ${ }^{42}$ Muchos mercaderes de México casaron a sus hijas con sus sobrinos, de modo que a su muerte el sobrino y yerno quedaba a cargo de la administración de los negocios de la heredera. La transmisión indirecta de las empresas y la endogamia garantizaban la conservación del patrimonio y daban cohesión a la familia. Los mercaderes favorecían la unificación del Imperio, al mantener el comercio en manos de peninsulares convencidos de la necesidad de perpetuar el vínculo con el linaje originario. ${ }^{43}$

José de Retes Largacha, natural de la villa de Arciniega, provincia de Álava, y Luis Sánchez de Tagle, originario del pueblo de Santillana, en las montañas de Burgos, basaron sus empresas en las relaciones de parentesco, los vínculos matrimoniales y de paisanaje. El primero pidió que enviaran a México a los hijos de su hermana, Dámaso y Damián de Zaldívar y Retes, quienes en 1662 se incorporaron a sus negocios. Al cabo de unos meses, el patriarca se asoció con Damián, a quien nombró teniente general del oficio de apartador de metales y lo puso a cargo de la agencia de San Luis Potosí. ${ }^{44}$ Retes Largacha y Quesada Cabreros concluyeron sus negocios en 1667. Dos años después, Retes acogió a los hijos de su hermano mayor, Gabriel y José Sáenz de Retes. Al primero lo colocó como administrador de la tienda que había constituido en San Luis Potosí, en sociedad con Dámaso de Zaldívar. En 1677 Retes Largacha estableció otra compañía con sus sobrinos José Sáenz de Retes y Dámaso de Zaldívar, destinada a habilitar la minería, comprar plata y amonedarla. ${ }^{45}$

42 Imizcoz Beunza y Elecalde, 2002, 41-66; Domínguez Martín, 2006, 75-94.

43 Bertrand, 1999.

44 El apartador general estableció oficinas en San Luis Potosí, en cuyas minas había cantidades considerables de oro. Elhuyar, 1979, 47, 48.

45 Retes Largacha capitalizó dicha empresa mediante la concesión de un préstamo a sus sobrinos por 400,000 pesos, al 5\% de interés, mientras que los últimos sólo aportaron 16,000 pesos cada uno. Huerta, 1997, 77 y Huerta, 2003, 25, 26. 
Por otra parte Luis Sánchez de Tagle, en 1684, encomendó a su sobrino Francisco Díaz de Tagle la administración del almacén de ultramarinos de la ciudad de México. ${ }^{46}$ En adelante, Sánchez de Tagle se concentró en el avío de la minería y la compra de plata para acuñarla. Otro sobrino, Pedro Sánchez de Tagle y Bustamante, se estableció en la misma casa desde el inicio de la década de 1680 y en 1691 contrajo matrimonio con su prima Luisa, la única hija del patriarca ${ }^{47}$ A la muerte de don Luis, acaecida en 1710, Luisa quedó como heredera de todos los bienes y el título de marqués de Altamira, que había obtenido su padre en 1704. A partir de entonces, don Pedro se hizo cargo de la administración del enorme patrimonio que habían constituido los Sánchez de Tagle. ${ }^{48}$

\section{Crédito y vínculos de confianza}

Las relaciones personales resultaron fundamentales para sostener el sistema de crédito que privaba en la economía de Nueva España, debido a la escasez de circulante y a la inexistencia de instituciones crediticias formalmente establecidas. Para financiar sus negocios, los tratantes de plata recibían préstamos de otros mercaderes y depósitos de rentistas por los que pagaban un 5\% de interés. Las corporaciones eclesiásticas eran las principales rentistas. El Juzgado de testamentos, capellanías y obras pías de la ciudad de México colocaba con los mercaderes los caudales de las fundaciones piadosas y religiosas que administraban, mientras que los conventos, las capellanías, los hospitales y colegios hacían lo mismo con los fondos que constituían parte de su patrimonio. Los miembros del clero secular y los oficiales reales ${ }^{49}$ también se destacaron entre los rentistas. Los mercaderes brindaban a sus acreedores como única garantía la confianza que derivaba de la reputación de su casa.

46 En 1706 Díaz de Tagle continuaba a cargo del almacén de su tío. Véase Valle Pavón, 2004, 941-964, 955 .

47 Don Pedro nació el 7 de julio de 1661 en Santillana, al igual que su tío Luis. Poder para testar otorgado por Pedro Sánchez de Tagle, México, 15 de diciembre de 1723 y Testamento de Pedro Sánchez de Tagle, 18 de diciembre de 1723. Archivo General de Notarías, Ciudad de México (en adelante AGNM), notario 392, Antonio Alejo Mendoza, 2605.

48 Testamento de Luis Sánchez de Tagle, México, 28 de abril de 1714. AGNM, notario 692 Francisco de Valdés, 4705, s/ f.

49 Un sujeto «involucrado en la distribución de azogue» colocó con Luis Sánchez de Tagle 12,000 pesos en 1687, y 20,000 pesos más en 1699. Huerta, 2003, 22. 
El prestigio de Luis Sánchez de Tagle y las relaciones que estableció con la jerarquía eclesiástica, le permitieron recibir capitales considerables de los mismos prelados y de las comunidades que estaban bajo su tutela. El chantre de la catedral de la ciudad de México, Manuel Escalante Mendoza, colocó con don Luis 17,000 pesos. ${ }^{50}$ Entre los conventos de monjas que invirtieron parte de sus caudales con el poderoso mercader pueden mencionarse La Encarnación, Santa Teresa y La Concepción..$^{51}$ Por la cercanía que tenía Sánchez de Tagle con los frailes dominicos fue nombrado diputado de la mesa directiva de la archicofradía de Nuestra Señora del Rosario, ${ }^{52}$ la cual colocó en su negocio 30,000 pesos a interés. ${ }^{53}$

Cuando Sánchez de Tagle falleció, en 1710, había constituido un «banco de plata», como se denominaba a las dos o tres empresas de la época que destinaban grandes capitales al otorgamiento de crédito a los mineros y la compra de plata para amonedar. No existen registros sobre las operaciones que realizaba el banco de plata del mercader cántabro, sin embargo, en el inventario de bienes que se realizó a raíz de su muerte se registran 740,000 pesos en depósitos y escrituras de obligación. ${ }^{54}$ Joseph de Torres y Vergara, juez del tribunal de testamentos, capellanías y obras pías del arzobispado de México y comisario general de la Bula de la Santa Cruzada ${ }^{55}$ junto con Pedro Sánchez de Tagle, formó parte del pequeño grupo de criadores y tratantes de ganado que abasteció de carne al gran mercado de la ciudad de México, cuando menos entre 1708 y $1716 . .^{56}$ El ministro canalizó al banco de plata de los Tagle los caudales de su propiedad y parte de los que pertenecían al tribunal que administraba. Poco antes de fallecer, don Pedro nombró a Torres y Vergara uno de sus co-albaceas tes-

50 Ibidem, 20-23.

51 Una huérfana que don Luis había acogido en su casa profesó en dicho convento con la dote que el mercader le otorgó. Testamento de Luis Sánchez de Tagle, México, 28 de abril de 1714. AGNM, notario 692 Francisco de Valdés, 4705, s/f.

52 Don Luis fue sepultado en la capilla de Nuestra Señora del Rosario, sede de la mencionada hermandad, ubicada en el convento de Santo Domingo. Testamento de Luis Sánchez de Tagle, México, 28 de abril de 1714. Ibidem.

53 Vargas-Lobsinger, 1992, 40.

54 Asimismo debía 416,734 pesos por cuentas «de libro» sin réditos. Poder para testar, México, 30 de junio de 1710 y Testamento de Luis Sánchez de Tagle, México, 28 de abril de 1714. AGNM, notario 692 Francisco de Valdés, v. 4705, s/f.

55 En 1723 Torres y Vergara también era canónigo doctoral y maestre escuela de la catedral de México, subdelegado apostólico y real, y jubilado de primeras leyes de la Universidad de México. Valle Pavón, 2006, 15-46.

56 Ibidem, 32-34. En 1702 Sánchez de Tagle empezó a comprar tierras para la cría de ganado y su comercialización en la ciudad de México, negocio que era sumamente rentable. 
tamentarios, declaró que tenía en su poder 20,000 pesos que le pertenecían «a lo que me puedo recordar», y mandó «que la cantidad que dijere dicho señor le debo, se le pague», así como los intereses que le adeudaba. ${ }^{57}$ Los caudales que los Tagle recibían al 5\% de interés anual, eran negociados a tasas mucho mayores, en razón de la escasez de circulante que se padecía en Nueva España, así como por los riesgos que se corrían en la habilitación de la minería y el tráfico comercial.

\section{Financiamiento de las remesas de mercurio}

Al inicio de la década de 1660 se presentó una grave escasez de azogue en Nueva España a causa de los problemas para financiar las minas de Almadén. ${ }^{58}$ El desabastecimiento del metal líquido limitaba la producción de la plata de baja ley, la cual sólo podía beneficiarse por el método de amalgamación. Muy probablemente a petición de los mercaderes de plata, el marqués de Mancera, en 1666, requirió al virrey del Perú el abasto urgente de mercurio de Huancavelica. El azogue peruano era de menor calidad que el de Almadén y su precio mucho más elevado, además de que su tráfico estaba prohibido porque encubría el intercambio ilícito de plata andina por bienes orientales. El azogue peruano arribó al puerto de Acapulco en $1670 .{ }^{59}$ Carlos II autorizó dicha remesa persuadido por el fiscal de Nueva España, ${ }^{60}$ en quien, probablemente, influyeron los mercaderes de plata.

Las relaciones entre el consulado y las autoridades virreinales habían sido muy tensas a raíz del cierre del tráfico con Perú, impuesto a fines de

57 AGNM, notario 392, Antonio Alejo Mendoza, v. 2605. Testamento de Pedro Sánchez de Tagle, 18 de diciembre de 1723 .

58 Entre 1640 y 1660 se enviaron de Cádiz a México 11,800 quintales de azogue por quinquenio, en promedio, mientras que de 1661 a 1665 sólo se remitió una media quinquenal de 6,500 quintales. En 1663 el comandante de la flota de Nueva España se quejó de las dificultades para colocar las mercancías en Veracruz por la falta de plata que había ocasionado la carencia de azogue. Lang, 1977, 176, 353. Pacífico.

59 Dicha partida no se liquidó por motivos burocráticos y por la amenaza de piratas en el

60 En 1667 el fiscal de Nueva España se opuso al empleo de mercurio de Huancavelica porque propiciaba el comercio ilegal de bienes orientales. En 1669 el fiscal presentó un informe en el que mostró que las telas chinas no competían con las europeas, mientras que la prohibición del comercio con Perú había hecho caer los ingresos fiscales del tráfico con Filipinas. Lang, 1977, 101$105,107-121$. 
la década de $1630 .{ }^{61}$ La situación había empeorado luego que quebró la administración del derecho de alcabalas de la administración de la ciudad de México que se había otorgado a dicha corporación de 1647 a 1661. Presumimos que el marqués de Mancera estrechó los vínculos con los representantes consulares por su interés en que el consulado volviera a hacerse cargo de la renta mencionada, luego de que, en 1672, cayó en bancarrota la gestión del ramo que estuvo a cargo de la ciudad. ${ }^{62}$ En el informe que Mancera escribió a su sucesor unos meses después, planteó que el cuerpo mercantil era «el único pilar» que podía salvar el asiento de las alcabalas de la «última ruina». ${ }^{63}$

En la década de 1670 se incrementó la producción argentífera en los principales distritos mineros como consecuencia de la combinación de los métodos de fundición y amalgamación, debido a la regularización del abasto de azogue. ${ }^{64}$ En 1676 y 1678 se recibió metal líquido de Cádiz y en 1677 de Huancavelica. ${ }^{65}$ El navío que condujo el mercurio andino, a su regreso fue descubierto en El Callao cargado de mercancías asiáticas. ${ }^{66}$ En consecuencia, en 1678 el rey ordenó que sólo en caso «muy preciso e inexcusable» se remitiera azogue peruano a Nueva España, mandato que fue reiterado en $1682 .{ }^{67}$ En la década de 1680 dicho producto continuó llegando de manera irregular, por lo que numerosas minas tuvieron que suspender los trabajos. ${ }^{68}$

61 Las transgresiones al tráfico intervirreinal dictadas en la década de 1620 fueron reiteradas en 1634 y 1636, sin embargo, los intercambios sólo pudieron suspenderse cuando el visitador Pedro de Quiroga tomó drásticas medidas, con el apoyo del virrey marqués de Cadereyta. Acerca de la proscripción del comercio Pacífico véase Valle Pavón, 2005, 213-240.

62 Desconocemos quienes estuvieron en la representación del consulado durante la administración de Mancera, sólo sabemos que José de Retes Largacha fue cónsul en 1670 y 1671 . Acerca de la administración del derecho de alcabalas véase Valle Pavón, 2003, 65-69 y Valle Pavón, 2009, 95-117.

63 «Relación que de orden del rey dio el virrey de México (don Antonio Sebastián de Toledo, marqués de Mancera) a su sucesor (el señor don Pedro Nuño Colón, duque de Veragua), en 22 de octubre de 1673», en 1991, 634, 635 .

64 Bakewell, 1976, 239, 265-270, 289-296, 300-304 y 322-325; Stein, 2002, 148-149.

65 Aun cuando en 1674 se reiteró la prohibición del tráfico inter virreinal, en 1677 se recibieron 3,500 quintales de azogue de Huancavelica y el siguiente año 1,580 quintales de Almadén. Lang, 1977, 104, 107-121; Bakewell, 1976, 234-236, 304.

66 Archivo General de Indias (en adelante AGI), Lima, 76, el virrey Melchor de Liñán y Cisneros al rey, 27 de agosto de 1678.

67 Lang, 1977, 105.

68 De Cádiz se recibieron 6,920 quintales de azogue entre 1681 y 1685 y 8,000 quintales de 1686 a 1690. De Huancavelica llegaron tres mil quintales en 1683 y tres mil más en 1685. Ibidem, 102, 107-121, 353; Bakewell, 1976, 234-236, 304. 
En la década de 1680 los tratantes de plata unieron su poder económico y financiero al control de los cargos de representación del consulado. Luego de una larga pugna por los oficios consulares, a fines de los años 1670 , los individuos situados a la cabeza de la corporación, entre los que se encontraba José de Retes Largacha, se aliaron para lograr que se modificara la normatividad electoral. En adelante el prior y los cónsules en funciones controlaron los comicios para asegurar la designación de sus sucesores. ${ }^{69}$ Como puede verse en el cuadro número 3, los mercaderes de plata y sus aliados desempeñaron los oficios de prior y cónsul en el periodo de 1686 a 1703, en el que rigieron las nuevas reglas de elección. El cambio político favoreció la negociación con los virreyes en relación con el pago de las remesas del metal líquido, al garantizar continuidad en la representación corporativa. El conde de Monclova (1686-1688) y el conde de Galve (1688-1696) consiguieron azogue andino pagándolo a su arribo en Acapulco con el respaldo de los mercaderes de plata y el cuerpo mercantil. ${ }^{70}$ Este tráfico debió haber propiciado el comercio ilícito con el Perú.

Los mercaderes más acaudalados solían otorgar a los virreyes préstamos a corto plazo sin interés, generalmente si no habían llegado a la capital los fondos de las cajas del interior. ${ }^{71}$ Cuando menos, a partir del inicio de la década de 1680 los principales financieros de los virreyes fueron el vizcaíno Juan de Urrutia Retes y el montañés Luis Sánchez de Tagle, cónsul del tribunal mercantil en 1686-1687. Entre 1683 y 1690 ambos prestaron a la real Hacienda 378,000 pesos libres del pago de réditos, para satisfacer diversas urgencias. ${ }^{72}$ Los servicios financieros que prestó Urrutia Retes influyeron para que el monarca le otorgara el título de marqués de Villar del Águila en 1689, unos meses antes de su muerte. ${ }^{73}$ En razón de su interés en la producción de plata, presumimos que Sánchez de Tagle y Urrutia Retes contribuyeron de manera significativa para reunir 100,000 pesos que el consulado prestó para saldar poco más de 1,600 quintales de

69 Véase al respecto Valle Pavón, 2003, 69-70.

70 Gutiérrez Lorenzo, 1995, 354. En 1688 se recibieron tres mil quintales de azogue de Perú. Lang, 1977, 102.

71 José de Retes Largacha y su socio José de Quesada Cabreros, formaron parte del pequeño grupo de «banqueros de los virreyes» en la década de 1650. Hoberman, 1991, 176, 177.

72 AGN, Vínculos, 112-9. Cuando se otorgó el título de marqués de Altamira a Luis Sánchez de Tagle, entre sus principales servicios se destacaron dichos préstamos. Concesión del título de marqués de Altamira, Madrid, 23 de diciembre de 1704.

73 El fallecimiento de dicho mercader ocurrió en 1690. Huerta, «Redes», 2007, 100. 
GUILLERMINA DEL VALLE PAVÓN

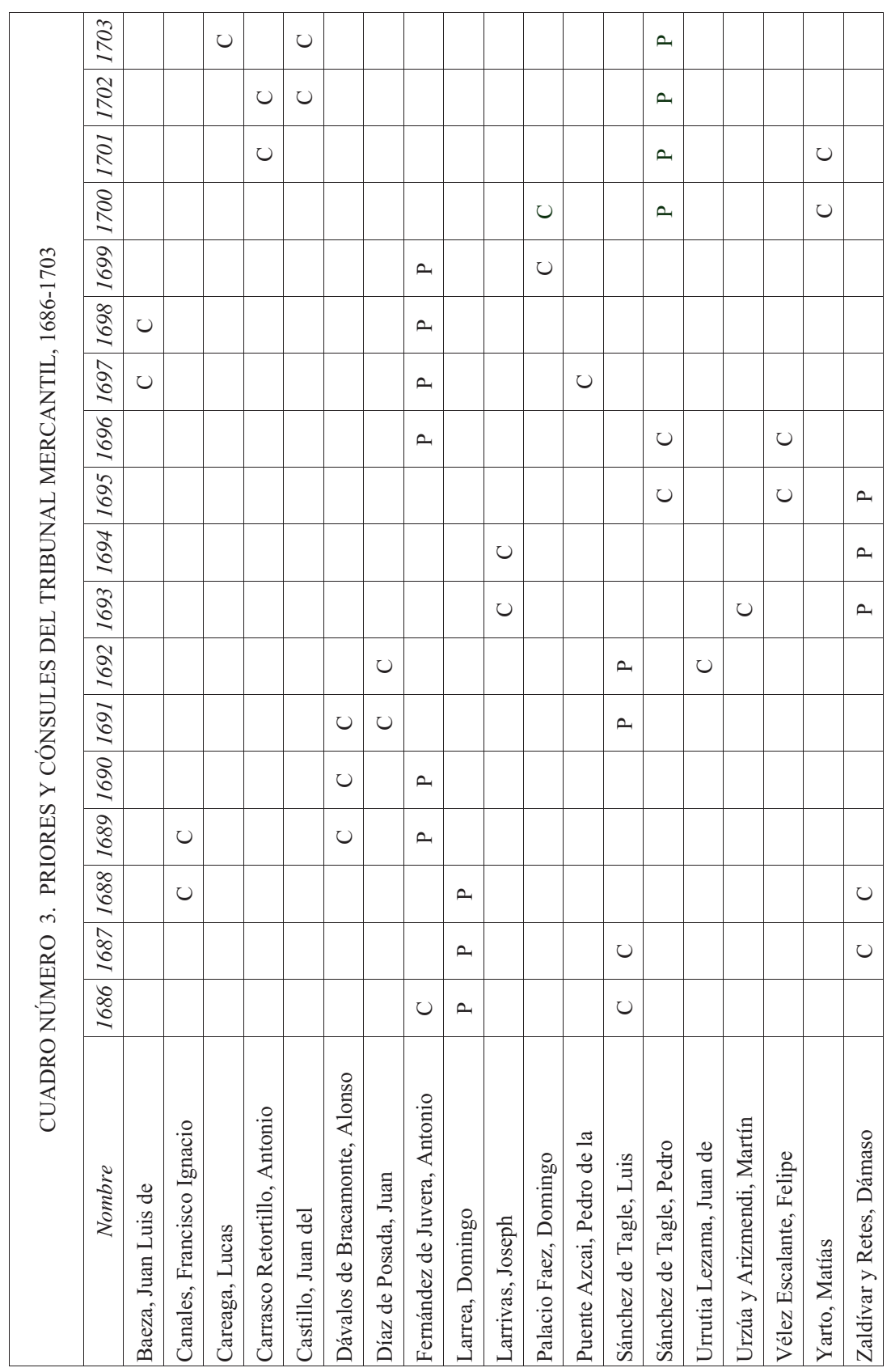

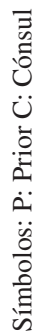


azogue, de los 3,258 quintales que llegaron en la flota de 1689, así como su transporte a la ciudad de México. ${ }^{74}$

Siendo prior Luis Sánchez de Tagle arribaron procedentes de Huancavelica 3,000 quintales de mercurio en 1691 y otra suma igual al año siguiente. Los 309,000 pesos que importó el metal líquido que se recibió el segundo año, fueron saldados a su entrega con letras a cargo de los miembros del cuerpo mercantil. ${ }^{75} \mathrm{Al}$ parecer, en compensación por dicho servicio, el virrey autorizó a mineros y mercaderes a comprar azogue en la capital para revenderlo, medida que propició la concentración del metal por parte de los mineros que garantizaban su pago. ${ }^{76}$ Aun cuando en las explotaciones de Sombrerete, Sonora y Chihuahua predominaba la producción de plata por el método de fundición, el empleo del mercurio también tenía un papel importante.

En 1692 el virrey conde de Galve planteó al Consejo de Indias que la falta de mercurio limitaba la producción argentífera y promovió la compra del metal en el Oriente, con el apoyo de Fausto Cruzat y Góngora Rada, el gobernador de Filipinas (1690-1702) con quien Luis Sánchez de Tagle tenía vínculos estrechos. El erario virreinal remitió a Manila 12,000 pesos para la compra de 100 quintales de azogue pero, sin embargo, sólo se pudieron adquirir 53 quintales, los cuales se perdieron cuando el galeón El Santo Cristo de Burgos se incendió antes de llegar a Acapulco, en 1693. La situación se complicó poco después porque los problemas técnicos en las minas de Huancavelica obligaron a suspender el envío de mercurio a Nueva España. ${ }^{77}$

A instancias del conde de Galve, el Consulado promovió la explotación de yacimientos de azogue en el virreinato. El prior Dámaso Zaldívar y Retes firmó un contrato con dos mineros peruanos para que produjeran el metal líquido, no obstante, la empresa fracasó. En 1696, siendo cónsules Pedro Sánchez de Tagle y Felipe Vélez Escalante, mercaderes de plata de origen montañés, el tribunal mercantil ofreció 2,000 pesos de gratificación

74 Gutiérrez Lorenzo, 1995, 355, 356.

75 En 1692 el conde de Galve autorizó que el azogue procedente de Perú se remitiera directamente de Acapulco a las cajas reales de los centros mineros. Ibidem, 357-359.

76 Acerca del mantenimiento de reservas de azogue en la ciudad de México, los conflictos a los que dio lugar y los intentos de descentralizar su distribución véase Lang, 1977, 205-210.

77 Gutierrez Lorenzo, 1995, 352; Lang, 1977, 102, 103, 105, 106, 141-144; Bakewell, 1976, 213, 214. 
por el descubrimiento y la explotación de minas de azogue, pero tampoco se obtuvieron resultados. ${ }^{78}$

La relevancia de la plata novohispana en el comercio atlántico condujo a los mercaderes de Sevilla a esforzarse por reactivar las minas de Almadén. En 1690 el consulado de Sevilla canalizó a dichos yacimientos un crédito por 400,000 pesos. Ante la falta de resultados, en 1694 se hizo cargo de la gestión de dichas minas. ${ }^{79}$

Es posible que Dámaso de Zaldívar y Retes, siendo prior, pagara 292,500 pesos que importaron 3,000 quintales de mercurio andino que arribaron al puerto de Acapulco en 1693. ${ }^{80} \mathrm{El}$ año siguiente, Dámaso de Zaldívar y los cónsules Joseph de Larribas y Felipe Vélez de Escalante se comprometieron a liquidar azogue que se recibiera en el término de seis meses. ${ }^{81}$ Zaldívar y Retes y su primo Joseph Sanz de Retes, prestaron de manera conjunta a la corona 627,000 pesos en diversas ocasiones, antes de 1695, año en que ambos fallecieron. ${ }^{82}$ Entre 1695 y 1699 arribaron diversas remesas del metal líquido procedentes de Cádiz, sobre cuyo pago no tenemos noticia. ${ }^{83}$

En 1700 el prior Pedro Sánchez de Tagle tuvo dificultades para prorratear 322,000 pesos que importó el azogue de Almadén, entre los cónsules, diputados y electores que habían contraído la obligación. El prior efectuó dicho pago de su propio bolsillo y, unos meses después, adelantó poco más de 258,800 pesos para liquidar 3,000 quintales de mercurio de Huancavelica. ${ }^{84}$

Presumimos que los mencionados priores estuvieron dispuestos a financiar el pago del azogue porque, en 1694, el Consulado se había hecho cargo de la administración del derecho de alcabalas de la ciudad de México, cuya renta garantizaba el reembolso de los caudales adelantados. El virrey conde de Galve negoció ese arrendamiento del ramo alcabalatorio con el

78 AGN, AHH, 635-20. En la «prometedora» mina de San Gregorio se obtuvieron 20 quintales del metal. Ibidem, 213-218. Los yacimientos de Temascaltepec y Chilapa resultaron muy pobres. Antes se había tratado de explotar otros yacimientos en la misma zona de Chilapa. Bakewell, 211; Lang, 1977, 301-309, 330.

79 Lang, 1977, 70, 78-85.

80 Gutiérrez Lorenzo, 1995, 353-355.

81 AGN, AHH, 213-17.

82 Parte de dichos créditos se destinaron a financiar la defensa de los fuertes de La Habana y Santo Domingo, así como la Armada de Barlovento. Langue, 1999, 211.

83 Lang, 1998, 328, 329.

84 AGI, México, 741, «Representación de cónsules y diputados del consulado de México al rey en la que solicitan la prorrogación casi perpetua del cargo de prior en la persona de Pedro Sánchez de Tagle (1701)»; AGN, Consulados, 2-4, f. 13, «Razón aunque simple, verdadera de la franquía de dinero del consulado de México». Lang, 1977, 102, 103, 105, 106; Lohmann Villena, 1999, 461, 462. 
cuerpo mercantil, luego de que sus productos hubieran decrecido notablemente por la mala gestión de los oficiales reales. Con la nueva administración la corporación obtuvo importantes privilegios, entre los que se destacan la exención de rendir cuentas de su gestión y la conservación de los excedentes de la recaudación, ${ }^{85}$ mientras que el virrey contó con el crédito de la corporación. En 1697, el obispo virrey Juan de Ortega Montañés recomendó a su sucesor que atendiera a los mercaderes «con cuanta gracia hubiere lugar en lo posible por estar experimentado que el prior y cónsules, que [...] administran el asiento en su nombre, han procurado y procuran cumplir sus obligaciones y en los empeños de un señor virrey asistir no sólo a pagar en cada plazo la cantidad que le corresponde, sino hacer adelantamientos de un plazo o más, con toda voluntad y fineza». ${ }^{86}$

Los elevados productos que generaban las alcabalas en el distrito de la ciudad de México, que era el mayor centro de consumo y redistribución de bienes del virreinato, aseguraban al prior la restitución de los caudales que adelantaba al erario. Sánchez de Tagle no corría riesgos al otorgar cuantiosos préstamos para satisfacer las remesas de azogue, mientras se mantuviera a la cabeza del cuerpo mercantil. En 1701 don Pedro fue reelecto prior, a pesar de la oposición de los mercaderes de origen vizcaíno. En la elección de 1702 volvió a haber «contiendas por las parcialidades de montañeses y vizcaínos», ${ }^{87}$ no obstante el monarca autorizó que se volviera a nombrar prior a Sánchez de Tagle, muy probablemente por la relevancia que tenía el financiamiento que otorgaba al erario virreinal. ${ }^{88} \mathrm{El}$ mercader se mantuvo como prior hasta 1703 , por un periodo cercano a los cuatro años, ${ }^{89}$ aunque dicho oficio sólo se podía desempeñar durante un bienio.

La generosidad con que Pedro Sánchez de Tagle desembolsó, cuando menos, 580,800 pesos $^{90}$ para sufragar las remesas de azogue, muestra la

85 Valle Pavón, 2007, 969-1016 y Valle Pavón, 2009, 95-117, 103, 104.

86 «Relación del obispo-virrey Juan de Ortega Montañés a su sucesor», en Instrucciones y memorias, 1991, 713, 714.

87 Robles, 1946, 191.

88 AGN, AHH, 215-7, Libro de elecciones del Tribunal del Consulado; AGI, México, 741, «Representación del consulado al rey en la que solicitan la prorrogación casi perpetua del cargo de prior en la persona de Pedro Sánchez de Tagle».

89 El virrey duque de Alburquerque destituyó a Sánchez de Tagle del oficio de prior debido a un enfrentamiento personal con el clan al que pertenecía. Valle Pavón, 2004, 951, 952.

90 Puede tenerse una idea de la importancia de dicho monto, si tomamos en cuenta que, en toda la década de 1690, la Real Hacienda de Nueva España remitió a la metrópoli poco más de 2,740,000 pesos. Véase el cuadro 5.1. «Cálculo de la plata gubernamental embarcada a España y Filipinas desde Perú y Nueva España, 1591-1750», Klein, 1994, 134. 
magnitud de los intereses que tenía en la producción argentífera. Muy probablemente, a fines del siglo XVII los Tagle eran los principales aviadores de la minería y compradores de plata para amonedar. Como veremos a continuación, desplegaron una compleja estrategia para conseguir el metal blanco en grandes cantidades.

\section{Los «mercaderes de la Casa de Moneda»}

Como ya se ha indicado, la única Casa de Moneda de Nueva España se ubicaba en la ciudad de México. En ésta se fundía y acuñaba la plata, servicios por los que se descontaban los derechos de señoreaje y braceaje. ${ }^{91}$ Ambos procesos eran controlados por quienes detentaban los llamados oficios mayores de la Ceca: tesorero, ensayador, balanzario, tallador y guarda mayor. Durante el XVII y a principios del siglo XVIII la corona vendió los citados oficios mayores, gran parte de los cuales fueron adquiridos por un puñado de mercaderes acaudalados. ${ }^{92}$ Este hecho, unido a los préstamos que otorgaban a los oficiales y tenientes que desempeñaban las tareas relacionadas con el proceso de la acuñación, permitieron a los mercaderes controlar la institución. A fines del siglo XVII, la mayoría de los propietarios de esos oficios mayores eran mercaderes de plata de origen cántabro y vizcaíno, así como parientes de estos.

Los «mercaderes de la Casa de Moneda», como les llamó Louisa Hoberman, se hacían cargo de que se acuñaran los metales de su propiedad, los de otros tratantes y los de la corona. Los propietarios de los oficios mayores de la Ceca percibían ingresos muy elevados de manera legal y a veces ilícita. Cobraban las rentas asignadas a los cargos que habían adquirido y las comisiones por amonedar, además de beneficiarse por las variaciones que tenía la ley de la plata en pasta. Asimismo obtenían ganancias mediante la realización de fraudes en la acuñación y la evasión de los derechos correspondientes. ${ }^{93}$

91 El braceaje era un porcentaje del monto oficial de los metales amonedados con el que se retribuía al tesorero de la Ceca, quien controlaba dicha institución.

92 En 1585 la Real Hacienda vendió el oficio de tesorero en 130,000 pesos, más 20,000 pesos correspondientes a los esclavos y herramientas. En 1629 se pagaron 275,000 pesos por el mismo cargo. Hoberman, 1991, 83-85. El oficio de fundidor y ensayador mayor fue una excepción porque el mercader Melchor de Cuellar, que lo había adquirido en 1610, lo donó al monasterio de Carmelitas descalzas del Santo Desierto de la Provincia de San Alberto, en 1640. Peña, 1983, 137.

93 Hoberman, 1991 y Hoberman «Crédito», 1998, 75-77. 
El dominio que ejercían los mercaderes de la Ceca sobre el proceso de acuñación y las relaciones que mantenían con el resto de los oficiales de la institución, les permitían determinar la calidad de los reales que se acuñaban. Los productores de moneda fusionaban la plata que había sido ensayada y gravada, cuya ley estaba probada, con el metal de rescate que no había cumplido dichas condiciones, y con plata peruana que tenía menor grado de pureza. ${ }^{94}$ En consecuencia, no todas las monedas que se elaboraban en la Ceca de México cumplían con las condiciones impuestas por la corona. ${ }^{95}$

Francisco Antonio de Medina Picazo fue propietario del oficio de tesorero, ${ }^{96}$ que era el de mayor jerarquía, porque quienes lo detentaban ejercían la función de supervisar los procesos de fundición y acuñación. ${ }^{97}$ Medina Picazo y sus parientes más cercanos, establecieron vínculos matrimoniales con miembros del consulado de México, oficiales reales y locales del puerto de Veracruz. Muy probablemente dichas relaciones facilitaban el tráfico ilícito de la plata acuñada y en pasta con la que se pagaban los bienes introducidos vía contrabando. En 1682 Medina Picazo se casó con la hija del tesorero de la real caja de Veracruz. ${ }^{98}$ Poco después su hermana Juana, contrajo matrimonio con Joaquín de Zavaleta, mercader procedente de Vizcaya, que fue prior en 1710 y 1711. José de Zavaleta, pariente de Joaquín, fue regidor y alcalde ordinario de Veracruz y arrendó la recaudación de las alcabalas del puerto cuando menos de 1704 a 1722.99

94 AGN, Casa de Moneda, 311-6, testimonio dado por el escribano de la real Casa de Moneda, de la real ejecutoria ganada por don Francisco Fagoaga, año 1754.

95 Acerca de los trastornos que generaba en Cádiz la llegada de reales que no tenían el valor estipulado a fines del siglo XVII, véase Un Comerciante, s. f., 167, 168.

96 Según vimos, el oficio de tesorero fue posesión del mercader Juan Lorenzo de Vera durante poco más de treinta años (véase nota n. ${ }^{\circ} 10$ ); poco después de su muerte, acaecida en 1659 o 1660 , el mercader Juan Vásquez de Medina lo compró en subasta a nombre de su hijo, Francisco Antonio de Medina Picazo. Luego de una larga disputa por dicho remate, Francisco Antonio Medina Picazo fue ratificado como tesorero de la Ceca. Artís Espriu, 1993, 224; Hoberman, 1991, 87; Guijo, 1953, 193; Huerta, 2007.

97 El tesorero contrataba a los acuñadores, quienes le rendían cuentas periódicamente. «Memorial de las noticias Sacras y reales escrito por D Juan Diez de la Calle, impreso en 1696», en Vetancurt, 1990, 103.

98 Acerca de los estrechos vínculos de los mercaderes de México con los oficiales de Veracruz, y la forma en que estas relaciones propiciaban el contrabando y la defraudación fiscal, véase Bertrand, 1999, 237-239.

99 José de Zavaleta arrendó las alcabalas en sociedad con su suegro Francisco de Aguirre Gomendio. Real cédula del asiento de alcabalas de la Veracruz, San Lorenzo, 28 de agosto de 1723. AGI, Escribanía, 198B, 84v-105v. Auto de los oficiales reales de Veracruz, 17 de septiembre de 1723. AGI, México, 770. Agradezco a Bernd Hausberger haberme facilitado ambas referencias. 
Juan de Urrutia Retes, otro mercader de origen vizcaíno, adquirió el oficio de guarda mayor de la Casa de Moneda. Según vimos, Urrutia Retes fue uno de los principales compradores de plata en sociedad con Luis Sánchez de Tagle y recibió el título de marqués de Villar del Águila, en 1689 , por el apoyo financiero que prestó al virrey durante varios años. A su muerte, acaecida en 1690, su sobrino Juan Antonio de Urrutia heredó todos sus bienes, incluido el cargo de guarda mayor de la Ceca, cuya propiedad conservaba en $1728 . .^{100}$

El oficio de apartador general de metales también formaba parte de la Casa. ${ }^{101}$ José de Retes Largacha había comprado en 1655 dicho cargo, cuya posesión a perpetuidad le fue confirmada en 1680. Cuando Retes falleció, en 1685, dejó el oficio de apartador a su sobrino Dámaso de Zaldívar y Retes. Este legó a su hijo Francisco Antonio Bernardino de Zaldívar la «casa del apartado» en 1695, cuya propiedad fue ratificada en 1696. Siendo Francisco Antonio menor de edad, Diego de Zaldívar se hizo cargo de la administración del «apartado». Cuando el primero profesó como sacerdote, en 1706, arrendó el oficio a su paisano Francisco de Fagoaga, quien recibió la cesión y traspaso del mismo en $1718 .^{102}$

Luis Sánchez de Tagle fue nombrado por el virrey «amonedador de las platas del monarca», muy probablemente en reconocimiento por los importantes servicios financieros que le prestaba. ${ }^{103} \mathrm{La}$ tesorería de la ciudad de México entregaba a don Luis el metal en barras que se había recaudado, y éste lo restituía en reales. El mercader obtenía ganancias de consideración por los grandes volúmenes de plata que el erario le confiaba para labrar. Además, como sucedía con la acuñación de la plata perteneciente a otros mercaderes, Sánchez de Tagle se beneficiaba de las variaciones en la ley que tenía el metal en pasta. ${ }^{104}$

También Luis Sánchez de Tagle apoyó a su sobrino y yerno, Pedro Sánchez de Tagle y Bustamante, para que adquiriera el oficio de tallador mayor de la Casa de Moneda, el cual generaba un rendimiento anual de

100 AGN, Casa de Moneda, 311-6, autos sobre fraude en la Casa de Moneda.

101 Ibidem. Fonseca y Urrutia, 1845, 142.

102 Entonces se autorizó a Fagoaga suprimir la oficina del Apartado de San Luis Potosí y, en caso de ser necesario, ampliar la de México. Huerta, 1997, 85; Elhuyar, 1979, 47, 48; Fonseca y Urrutia, $1845,156-158$.

103 AGI, México, 479, expediente sobre la restitución de «los Tagles»,

104 Es importante hacer notar que a principios del XVII cuatro o cinco mercaderes se hacían cargo de amonedar la plata del erario virreinal, función que desempeñaba únicamente Sánchez de Tagle a fines del mismo siglo. Hoberman, 1991, 91-93 y Hoberman, 1998, 76-78. 
10,000 a 11,000 pesos. ${ }^{105}$ En 1700 don Luis prestó a su sobrino Pedro 55,000 pesos para que completara los 90,000 que tenía que pagar por el traspaso de dicho oficio mayor. ${ }^{106}$ Siete años después, Pedro Sánchez de Tagle obtuvo la posesión del cargo de tallador mayor a perpetuidad, mediante el pago de 32,000 pesos al rey. ${ }^{107}$ Puede tenerse una idea de la cantidad de reales que labraban los Tagle si consideramos que en 1710, año en que falleció don Luis, éste tenía en existencia 307,288 pesos «en plata y oro acuñados y por acuñar». ${ }^{108}$ Según vimos, para los mercaderes de plata resultaba fundamental contar con el apoyo de los agentes del erario y los alcaldes mayores para obtener el metal de rescate que no había pagado los derechos reales. Pedro Sánchez de Tagle, el tallador mayor de la Ceca, casó a su segunda hija María Manuela con Juan Manuel Argüelles y Miranda, sobrino de Melchor de Miranda y Solís, propietario del oficio de tesorero de la real caja de Pachuca, ${ }^{109}$ distrito minero en el que Luis Sánchez de Tagle poseía dos haciendas de fundición. ${ }^{110}$ Según vimos, por la relevancia de la producción argentífera de Pachuca, el hermano del mercader de plata Domingo Larrea, había sido el anterior tesorero de la caja en cuestión. ${ }^{111}$ En 1710, poco antes de fallecer, Miranda y Solís, cuyos hijos eran menores de edad, designó a su sobrino Juan Manuel Argüelles y Miranda, su sucesor en el oficio de tesorero de la caja regia de Pachuca. ${ }^{12}$

105 Gemelli Carreri, 1983, 100-103.

106 AGNM, Notario 692, Francisco de Valdés, 4705. A la muerte de Luis Sánchez de Tagle, acaecida en 1710 , su sobrino no había saldado la deuda en cuestión. Testamento de Luis Sánchez de Tagle, 28 de abril de 1714.

107 Biblioteca Nacional de Madrid (en adelante BNMa), mss. 18646, 9. El propietario del oficio de tallador mayor, Diego Manuel Carvallido, pidió a Pedro Sánchez de Tagle 90,000 pesos para saldar sus deudas, a cambio de lo cual le traspasó el oficio mencionado con todos sus emolumentos, utilidades y la prerrogativa de nombrar tenientes. «Título de tallador de la Casa de Moneda de México, concedido por Felipe V a D. Pedro Sánchez de Tagle y sus herederos. Madrid, 29 de enero de 1708».

108 AGNM, notario 692 Francisco de Valdés, v. 4705, s/f. Testamento de Luis Sánchez de Tagle, México, 28 de abril de 1714.

109 Miranda y Solís había adquirido dicho cargo en 1684, luego de haber ejercido funciones subalternas en dicha caja durante varios años. Bertrand, 1999, 225-227.

110 AGNM, notario 692 Francisco de Valdés, v. 4705, s/f. Testamento de Luis Sánchez de Tagle, México, 28 de abril de 1714.

111 Rubial García, 1992, 7, 14-16.

112 Bertrand, 1999, 226, 227. La fianza para recibir su nombramiento en la real caja de Pachuca se encontraba entre las más elevadas. Ibidem, nota 21, 244; Lang, 1977, 231. 
En 1712 se descubrió que Pedro Sánchez de Tagle había enviado de Pachuca a la ciudad de México varias barras de plata sin quintar, acerca de lo cual «no se ha hablado por ser muy común y ordinario». ${ }^{113}$ Presumimos que don Pedro podía extraer de Pachuca la plata que no había sido gravada en razón de la estrecha relación que tenía con su yerno Juan Manuel Argüelles y Miranda, quien llegó a ser contador y juez de la real Hacienda y Caja de dicha población. ${ }^{114}$ Muy probablemente, la plata que había evadido el pago de derechos en Pachuca se destinaba a la Ceca, en donde el tallador mayor Pedro Sánchez de Tagle tenía oportunidad de labrar metales que no habían sido ensayados, ni gravados.

Pedro Sánchez de Tagle estaba protegido por los estrechos vínculos personales que tenía con el virrey duque de Linares (1711-1716). Este apreciaba al marqués consorte de Altamira de manera especial, entre otras razones, porque le había ofrecido su apoyo cuando se había perdido la nave almiranta de Barlovento, durante la Guerra de Sucesión, y cuando la flota a cargo de Juan de Uvilla había sido alcanzada por un huracán en Las Bahamas. ${ }^{115}$ La confianza que tenía el duque en don Pedro se puso de manifiesto en 1712, cuando le pidió que invitara a la minería y el comercio del real de Pachuca a acogerse «al indulto que les ofrecía», para impedir que el visitador Francisco de Pagave, que iba a realizar una investigación sobre la situación del real erario en Pachuca, impusiera medidas drásticas, como había hecho en Zacatecas. ${ }^{116} \mathrm{Al}$ final de su mandato, Linares recomendó ante su sucesor a Pedro Sánchez de Tagle, como uno de los pocos sujetos en quienes podría confiar verdaderamente. ${ }^{117}$

113 En 1712 el visitador Francisco de Pagave informó al rey que en la Casa de moneda «se labraba plata que no había sido quintada», parte de la cual se vendía a los cargadores de flotas y a los plateros de México. Gómez, 1979, 88, 89.

114 Don Pedro prestó a su yerno sumas cuantiosas para que fomentara la cría de ganado, como parte de los negocios a los que se dedicaba la familia. Valle Pavón, 2006, 32-34.

115 Los mercaderes Domingo de la Canal y Luis de Monterde también habían brindado su apoyo al virrey, quien censuraba al resto de los «principales» porque sólo trataban «de acaudalar tesoros y ostentar caballería» y no contribuían cuando se presentaban las ocasiones más precisas. Instrucción del duque de Linares gobernador de la Nueva España, para su sucesor, con descripción geográfica y política de su gobierno e informe de los males que padecía, México, 22 de marzo de 1723, BNMa, mss. 2929, 80, 127.

116 Gómez, 1979, 78-80, 88, 89.

117 BNMa, mss. 2929, 80, 127. Instrucción del duque de Linares, El virrey se refirió en particular a la opinión de Sánchez de Tagle sobre el abasto de maíz a la capital, a fin de prevenir las épocas de escasez. 


\section{Consideraciones finales}

A través del análisis de las redes de negocios y los vínculos personales que establecieron los mercaderes de la ciudad de México vimos la forma en que lograron concentrar la mayor parte de la plata que se producía en Nueva España. En la segunda mitad del siglo XVII, dichos empresarios configuraron complejas mallas de negocios, a través de las cuales controlaron los circuitos comerciales y crediticios asociados a la explotación minera. La venalidad de las magistraturas y los oficios públicos, así como la exigencia de fianzas a los funcionarios del erario, posibilitaron a los mercaderes para establecer relaciones de clientela a través de las cuales penetraron la estructura administrativa y judicial del virreinato. Al respecto sería conveniente profundizar en el conocimiento del papel que jugaron la familia, el paisanaje y el compadrazgo mediante el examen de documentos notariales y otras fuentes. La habilitación de la minería y el control de los metales acrecentaron los recursos y el poder político de los tratantes de plata, en detrimento de la autoridad formal de la monarquía y de los ingresos del real erario. Las autoridades reales eran conscientes de esta situación, pero sabían que el funcionamiento de la economía virreinal, así como ciertas funciones administrativas y de gobierno, dependían de dichos mercaderes. La influencia política que tuvieron José de Retes Largacha y Luis Sánchez de Tagle en la administración de Nueva España se ilustra con claridad en los grafos que se presentan.

Los principales mercaderes de plata, que procedían de las montañas de Burgos y el señorío de Vizcaya, mantuvieron vínculos estrechos con sus familiares, con quienes estaban unidos por lazos de sangre y afinidad de valores. Para expandir sus negocios reclutaron a sus sobrinos seguros de su lealtad y de que tenían una férrea disciplina en el trabajo. Con el propósito de mantener el patrimonio dentro de la estirpe y reforzar el linaje, muchos mercaderes casaron a sus hijas con sus sobrinos. Así, a pesar de la autonomía con que operaban las oligarquías en Nueva España, la constitución de cadenas migratorias por parte de los mercaderes de México garantizó la cohesión del Imperio.

Ante la inexistencia de instituciones bancarias, los vínculos basados en la confianza resultaron fundamentales para que los tratantes de plata obtuvieran financiamiento y otorgaran crédito. Con el propósito de rentabilizar los fondos de que disponían, clérigos, comerciantes, funcionarios reales y otros rentistas articulados a las mallas de los mercaderes de pla- 
GUILLERMINA DEL VALLE PAVÓN

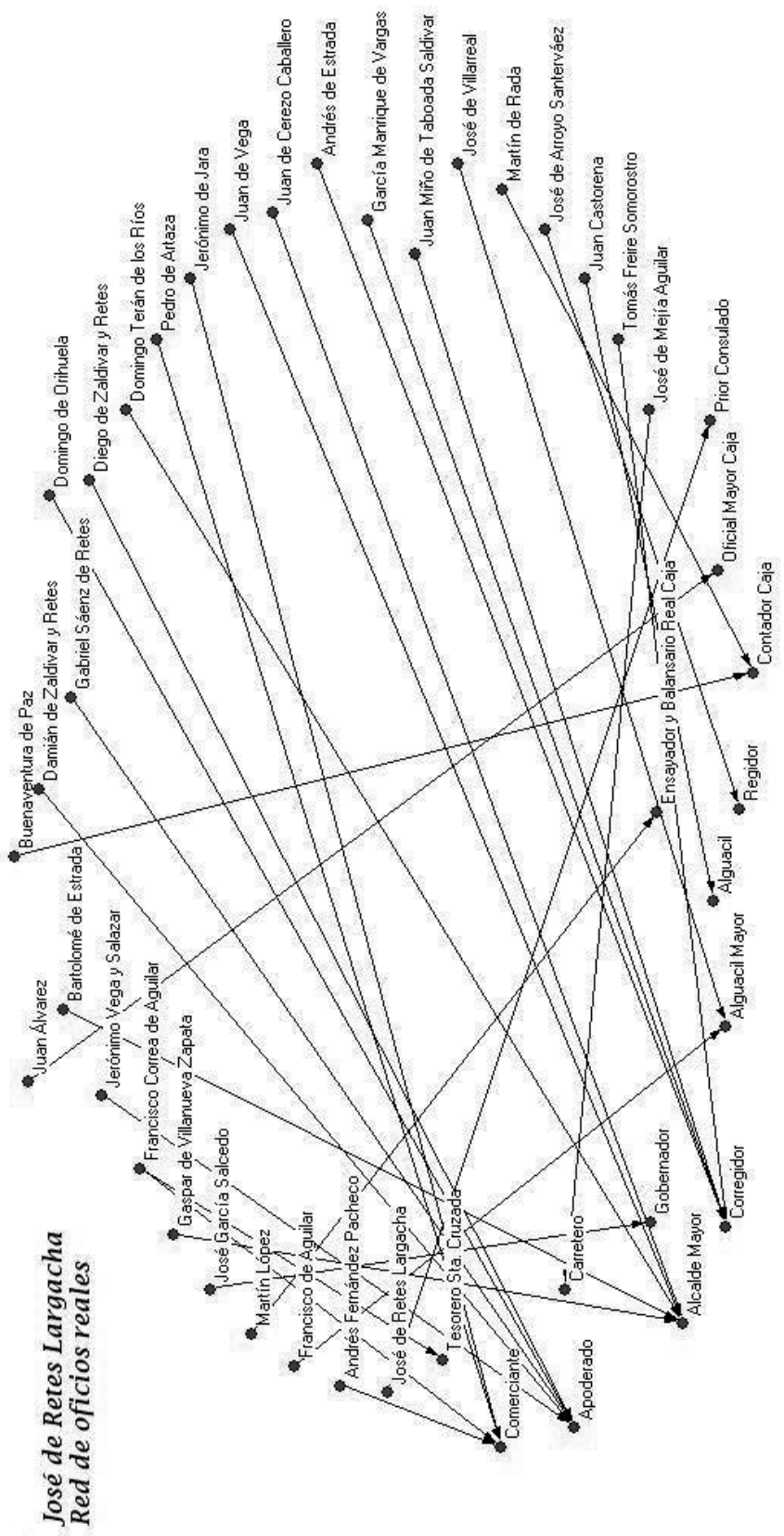


BASES DEL PODER DE LOS MERCADERES DE PLATA DE LA CIUDAD DE MÉXICO

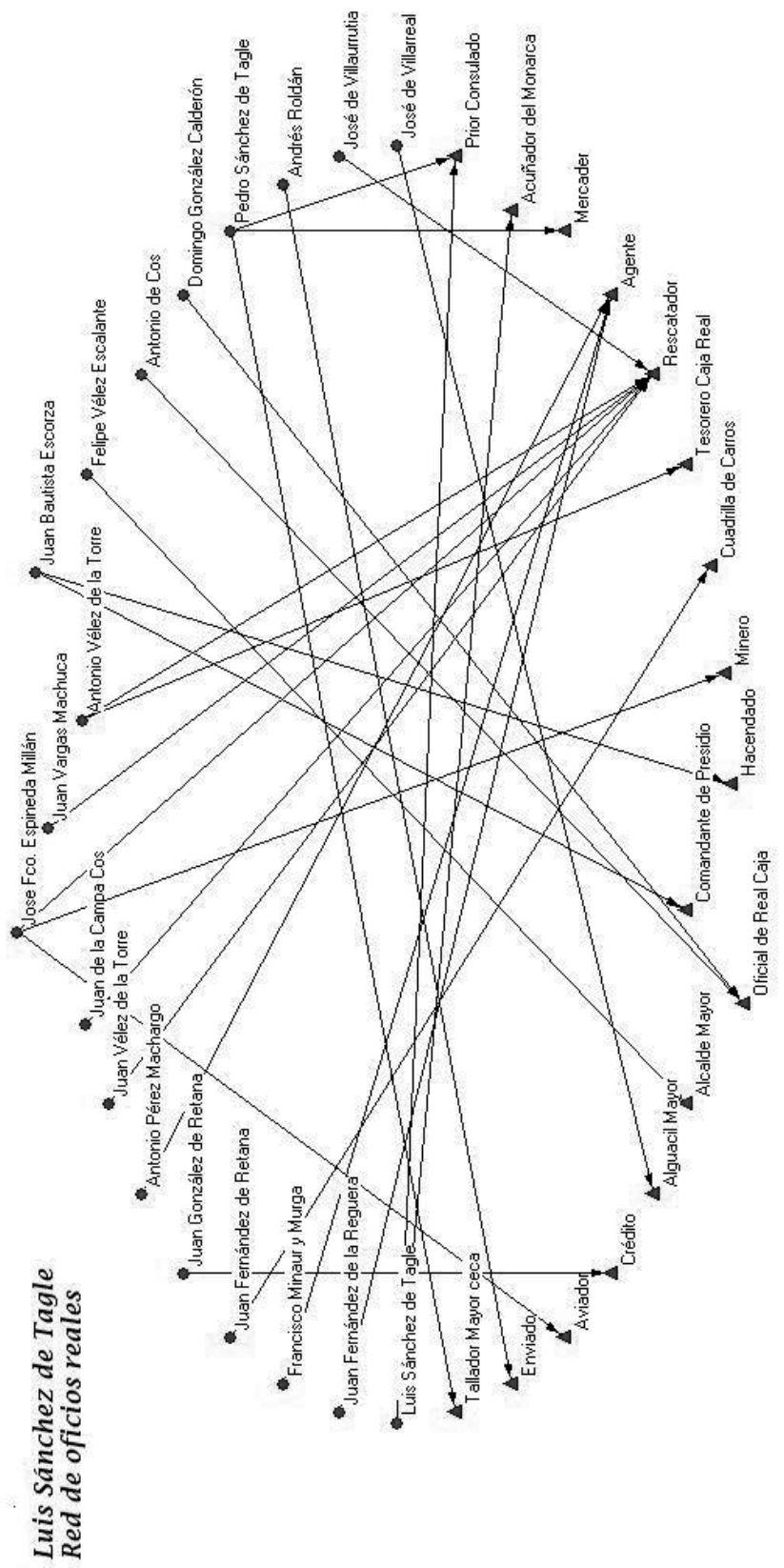


ta colocaban en sus casas dinero a cambio de una renta segura. Los empresarios más destacados establecieron estrechas relaciones de amistad y negocios con miembros de la jerarquía eclesiástica, quienes les confiaron cuantiosos fondos de su propiedad y de las instituciones que tenían a su cargo. Estos vínculos personales constituyeron parte del capital social que estos sujetos sociales legaban a sus descendientes.

A partir de la década de 1660 la producción argentífera en la Nueva España se vio restringida por la escasez de mercurio, aun cuando en algunos reales importantes, como Sombrerete, predominaba el método de fundición. Los mercaderes de plata negociaron con los virreyes el suministro de azogue de Almadén y Huancavelica, comprometiéndose a liquidar las remesas. Una vez que dichos mercaderes tomaron el control del Consulado, en la década de 1680, garantizaron la liquidación de las remesas del azogue. La recuperación del arriendo de la administración de las alcabalas de la ciudad de México dio seguridad a los priores para otorgar préstamos cuantiosos destinados a saldar el mercurio, porque disponían de los productos de la renta para reembolsarlos. El financiamiento que brindó el montañés Pedro Sánchez de Tagle en los últimos años del siglo XVII, le valió ser reelecto prior, yendo en contra de la normatividad y con la oposición del partido de los vizcaínos. El poder económico de los mercaderes de plata les permitía incidir en la definición de la política económica del virreinato y fortalecía su posición en el cuerpo mercantil.

La venalidad de los oficios reales hizo posible que un puñado de mercaderes y sus allegados controlaran la única Casa de Moneda de Nueva España. La propiedad de los oficios mayores de la Ceca, unida a otras estrategias, les permitió acuñar metales que no habían pagado derechos, determinar la calidad de la moneda novohispana y evadir los gravámenes por concepto de acuñación. Las redes establecidas por el tesorero y el tallador mayor de esa Casa, muestran cómo los poderosos mercaderes incorporaban a sus familias en los oficios reales y locales de importantes núcleos mineros y centros comerciales estratégicos. Tales vínculos facilitaban la realización de negocios ilícitos, entre los que se destacan la evasión de derechos reales y el contrabando de metales. Estas circunstancias permiten comprender porque el incremento de la producción argentífera que se generó en los últimos años del siglo XVII no se vio reflejado en las percepciones fiscales. Las relaciones clientelares que los mercaderes establecieron con autoridades de los distintos niveles de la administración de 
la Nueva España y el desempeño de algunos oficios claves muestran el papel fundamental que tuvieron en la orientación de la economía del virreinato.

Recibido el 3 de marzo de 2010 Aceptado el 31 de marzo de 2011

\section{Bibliografía}

Artís Espriu, Gloria: «La tierra y sus dueños: Chalco durante el siglo XVIII», en Tortolero, Alejandro (coord.): Entre lagos y volcanes. Chalco Amecameca: pasado y presente, México, El Colegio Mexiquense /H. Ayuntamiento constitucional de Chalco 1991-1993, 197-225.

Bakewell, Peter J.: Minería y sociedad en el México Colonial. Zacatecas (15461700), México, Fondo de Cultura Económica (FCE), 1976.

Bertrand, Michel: Grandeur et misères de l'office. Les officiers de finances de Nouvelle Espagne (XVIIe-XVIIIe siècles), Paris, Publications de La Sorbonne, 1999.

Bertrand, «Las redes de sociabilidad en la Nueva España: fundamentos de un modelo familiar en México (siglos XVII- XVIII)», en Arnauld, Charlotte; Bertrand, Michel; Langue, Frederique; Baudot, Georges (comps.): Poder y desviaciones: génesis de una sociedad mestiza en Mesoamérica, México, Siglo XXI Editores / Centro Francés de Estudios Mexicanos y Centroamericanos (CEMCA), 1998, 103-133.

Bustos Rodríguez, Manuel (estudio preliminar y edición): Un comerciante saboyano en el Cádiz de Carlos II, (Las memorias de Raimundo de Lantery 16731700), Cádiz, Ediciones de la Caja de Ahorros de Cádiz, 1983.

Domínguez Martín, Rafael: «Teorías migratorias y enseñanzas de la emigración cántabra a México», en Domínguez Martín, Rafael y Cerutti Pignat, Mario: De la colonia a la Globalización. Empresarios cántabros en México, Santander, Universidad de Cantabria, 2006, 75-94.

Elhuyar, Fausto de: Indagaciones sobre la amonedación en Nueva España, México, Miguel Ángel Porrúa, 1979 [Facsímil de la edición de 1818].

Fonseca, Fabián de y Urrutia, Carlos de: Historia General de la Real Hacienda, México, Imprenta de Vicente García Torres, en el ex-convento del Espíritu Santo, 1845, I.

García de León, Antonio: «La malla inconclusa. Veracruz y los circuitos comerciales lusitanos en la primera mitad del siglo XVII», en Ibarra, Antonio y Valle Pavón, Guillermina del (coords.): Redes sociales e instituciones consulares en el Imperio español, siglos XVII al XIX, México, Universidad Nacional 
Autónoma de México (UNAM), Facultad de Economía / Instituto de Investigaciones Dr. José Ma. Luis Mora, 2007, 41-84.

Gemelli Carreri, Giovanni Francesco: Viaje a la Nueva España, México, UNAM, 1983.

Gómez, Amalia: Visitas de la Real Hacienda novohispana en el reinado de Felipe $V$, Sevilla, Escuela de Estudios Hispano-Americanos (EEHA), CSIC, 1979.

Guijo, Gregorio Martín de: Diario 1648-1664, edición y prólogo de Manuel Romero de Terreros, México, Editorial Porrúa, 1953, II.

Gutiérrez Lorenzo, María del Pilar: «La Real Hacienda en la época del conde de Galve, 1688-1696», Novahispania, 2, México, 1995, 283-377.

Hernández Palomo, José J.: La renta del pulque en Nueva España, 1663-1810, Sevilla, EEHA, CSIC / Facultad de Filosofía y Letras, 1979.

Hausberger, Bernd e Ibarra, Antonio (coords.): Comercio y poder en América colonial: los consulados de comercio siglos XVIII y XIX. Elites comerciales, instituciones corporativas y gestión del cambio económico colonial, Madrid, Iberoamericana; Frankfurt, Vervuert Verlag; México, Instituto de Investigaciones Dr. José María Luis Mora, 2003.

Hoberman, Louisa Schell: Mexico's merchant elite, 1590-1660. Silver, state and society, Durham, Duke University Press, 1991.

Hoberman, «El crédito colonial y el sector minero en el siglo XVII: aportación del mercader de plata a la economía colonial», Martínez, Pilar y Valle Pavón, Guillermina del (coords.): El crédito en Nueva España, México, Instituto Mora / El Colegio de Michoacán / El Colegio de México / Instituto de Investigaciones Históricas de la UNAM. (Lecturas de historia económica mexicana), 1998, 61-82.

Huerta, María Teresa: «Redes mercantiles en torno a la plata en el norte minero novohispano. Segunda mitad del siglo XVII», en Redes sociales e instituciones comerciales en el Imperio Español, siglos XVII a XIX, México, 2007, 85-116.

Huerta, «Comerciantes en tierra adentro, 1690-1720», Valle Pavón, Guillermina del (coord.): Mercaderes, comercio y consulados de Nueva España en el siglo XVIII, México, Instituto de Investigaciones Doctor José María Luis Mora / CONACyT, 2003, 17-40.

Huerta, «Los Retes, prototipo del mercader de plata novohispano en la segunda mitad del siglo XVII», Los vascos en las regiones de México, siglos XVI-XX, México, UNAM / Ministerio de Cultura del Gobierno Vasco, 1997, III, 71-85.

Ibarra, Antonio y Valle Pavón, Guillermina del (coords.): Redes sociales e instituciones comerciales en el Imperio Español, siglos XVII a XIX, México, 2007.

Imizcoz Beunza, José María: «Comunidad, red social y elites. Un análisis de la vertebración social en el Antiguo Régimen», Elites, poder y red social. Las 
elites del País Vasco y Navarra en la Edad Moderna, Bilbao, Universidad del País Vasco, Servicio de Publicaciones, 1996, 13-50.

Imizcoz Beunza, José María y Guerrero Elecalde, Rafael: «A escala de Imperio. Familias, carreras y empresas de las elites vasconavarras en la monarquía Borbónica», Bertrand, Michel (coord.), Configuraciones y redes de poder. Un análisis de las relaciones sociales en América Latina, Caracas, Fondo Editorial Tropykos, 2002, 41-66.

Instrucciones y memorias de los virreyes novohispanos, Torre Villar, Ernesto de la, Estudio preliminar, coordinación, bibliografía y notas, México, Editorial Porrúa, 1991, I.

Klein, Herbert S.: Las finanzas americanas del Imperio Español, 1680-1809, México, Instituto de Investigaciones Dr. José María Luis Mora/Universidad Autónoma Metropolitana-Iztapalapa, 1994.

Lang, Mervin F.: Las flotas de la Nueva España (1630-1710): despacho, azogue, comercio, Sevilla, Muñoz Moya, 1998.

Lang, El monopolio estatal del mercurio en el México colonial (1550-1710), México, FCE, 1977.

Langue, Frederique: Los señores de Zacatecas. Una aristocracia minera del siglo XVIII novohispano, México, FCE, 1999.

Lohmann Villena, Guillermo: Las minas de Huancavelica en los siglos XVI y XVII, Lima, Pontificia Universidad Católica del Perú, 1999.

Muro Romero, Fernando: «La reforma del pacto colonial en Indias. Notas sobre instituciones de gobierno y sociedad en el siglo XVII», Jahrbuch für Geschichte Lateinamerikas, 19, 1982, 47-68.

Pazos y Pazos, María Luisa J.: El Ayuntamiento de la ciudad de México en el siglo XVII: continuidad institucional y cambio social, Sevilla, Diputación de Sevilla, 1999.

Peña, José F. de la: Oligarquía y propiedad en Nueva España, 1550-1624, México, FCE, 1983.

Ponce Leiva, Pilar y Amadori, Arrigo (coords.): «Dossier: Factores imprevisibles y márgenes de libertad de las redes sociales en la América Hispana», Revista Complutense de Historia de América, 34, Madrid, 2008, 11-128.

Ponce Leiva y Amadori, «Redes sociales y ejercicio del poder en la América Hispánica: consideraciones teóricas y propuestas de análisis», Revista Complutense de Historia de América, 34, Madrid, 2008, 15-42.

Robles, Antonio de: Diario de sucesos notables (1665-1703), edición y prólogo de Antonio Castro Leal, México, Editorial Porrúa, 1946, 3 tomos.

Rubial García, Antonio: «Un mercader de plata andaluz en Nueva España, Diego del Castillo (161?-1683)», Anuario de Estudios Americanos, XLIX, Sevilla, 1992, 143-170.

Stein, Stanley J.; Stein, Barbara H.: Plata, comercio y guerra. España y América en la formación de la Europa moderna. Barcelona, Editorial Crítica, 2002. 
Valle Pavón, Guillermina del: «Servicios fiscales y financieros del consulado de comerciantes de la ciudad de México en los siglos XVII y XVIII», en Garza, Gustavo y Sobrino, Jaime (coords.), Evolución del sector servicios en ciudades y regiones de México, México, El Colegio de México, 2009, 95-117.

Valle Pavón, «El régimen de privilegios del consulado de mercaderes de la ciudad de México», Rojas, Beatriz (coord.), Cuerpo político y pluralidad de derechos. Los privilegios de las corporaciones novohispanas, México, El Centro de Investigación y Docencia Económica/ Instituto de Investigaciones Dr. José Ma. Luis Mora, 2007, 155-187.

Valle Pavón, «Los excedentes del ramo de alcabalas. Habilitación de la minería y defensa del monopolio de los mercaderes de México en el siglo XVIII», Historia Mexicana, LVI, 2, (223), México, enero-marzo de 2007, 969-1016.

Valle Pavón, «Negocios y redes familiares y sociales de los Sánchez de Tagle, mercaderes de plata de México (1660-1724)», Domínguez Martín y Cerutti (eds.): De la Colonia a la globalización. Empresarios cántabros en México, Santander, 2006, 15-46.

Valle Pavón, «Los mercaderes de México y la trasgresión de los límites al comercio Pacífico en Nueva España, 1550-1620», Revista de Historia Económica, número extraordinario «La Economía en tiempos del Quijote», XXIII, Madrid, 2005, 213-240.

Valle Pavón, «El respaldo del Consulado de México para la Guerra de Sucesión Dinástica», Acosta, Antonio; González, Adolfo y Vila, Enriqueta (eds.): La Casa de la Contratación y la navegación entre Sevilla y las Indias, Sevilla, Universidad de Sevilla/ CSIC / EEHA / Fundación El Monte, 2004, 941-964.

Valle Pavón, «"Conflictos por la representación” y gestión del derecho de alcabalas, la transformación de la normatividad electoral del Consulado de México en el siglo XVII», Hausberger, Bernd e Ibarra, Antonio (coords.), Comercio y poder en América colonial: los consulados de comercio siglos XVIII y XIX. Elites comerciales, instituciones corporativas y gestión del cambio económico colonial, Frankfurt, Ed. Vervuert, Instituto de Investigaciones Dr. José María Luis Mora, 2003, 53-57.

Valle Pavón, «Expansión de la economía mercantil y creación del Consulado de México», Historia Mexicana, LI, 3, (202), México, enero-marzo de 2002, 517-557.

Vargas-Lobsinger, María: Formación y decadencia de una fortuna. Los mayorazgos de San Miguel de Aguayo y de San Pedro del Álamo, 1583-1823, México, UNAM / Instituto de Investigaciones Históricas, 1992.

Vetancurt, Agustín de: «Tratado de la ciudad de México y las grandezas que la ilustran después que la fundaron españoles», en La ciudad de México en el siglo XVIII (1690-1780). Tres crónicas, prólogo y bibliografía de Rubial García, Antonio, México, Consejo Nacional para la Cultura y las Artes, 1990, 37-129. 